\title{
Analyzing the Nonlinear Pricing of Liquidity Risk according to the Market State
}

\author{
Helena Chuliáa $\quad$ Christoph Koser ${ }^{\mathrm{b}}$ \\ Jorge M. Uribe
}

\begin{abstract}
This study examines the asymmetric impact of systemic liquidity on asset prices across market states. We use time-series conditional quantile regressions to estimate an otherwise traditional liquidity-augmented three-factor model for asset prices. We find the exposure of equity returns to systemic liquidity risk to be dependent on the market state. Contrary to general assumptions, our results show that liquidity is not always a relevant factor for explaining stock market returns and that it only becomes relevant when the market state is particularly good or particularly bad. Search-for-yield and flight-to-liquidity considerations help to explain our findings.
\end{abstract}

Keywords: systemic liquidity, asset prices, market state, time-series quantile regression.

JEL Codes: G01, G11, G12

\footnotetext{
a Riskcenter- IREA and Department of Econometrics, Universitat de Barcelona, Email: hchulia@ub.edu.

b Department of Econometrics, Universitat de Barcelona, Email: chkoser11@alumnes.ub.edu

c Faculty of Economics and Business Studies, Open University of Catalonia, Email: juribeg@uoc.edu
} 


\section{Introduction}

Long-Term Capital Management's related events at the end of 90's reminded us that investors have a marked preference for liquidity (Amihud et al., 2005). In episodes of extreme turmoil, when liquidity appears to vanish from financial markets, investors engage in fire sales and financial intermediaries seem to renounce their function as purveyors of liquidity for the rest of the economic and financial system (Hameed et al., 2010). During these periods of market liquidity dry-ups, risk aversion leads investors to rebalance their portfolios towards less risky and more liquid assets, episodes referred to, respectively, as flights-to-quality and flights-toliquidity (Baele et al., 2013; Beber et al., 2008). In contrast, when the market scenario and associated economic conditions are stable and optimistic, investors generally experience excess liquidity, leading them to rebalance their portfolios towards riskier and less liquid assets, with search-for-yield considerations in mind (Kiendrebeogo, 2016; Fratzscher et al., 2018). Both, flight-to-liquidity and search-for-yield are naturally associated with extreme market conditions, that is, bad and good, respectively.

For these reasons, the role played by liquidity as a factor-explaining asset prices should ideally be examined from a general perspective that allows for a changing (and non-linear) association between liquidity and prices. Yet, the study of the effect of systemic liquidity on asset prices has traditionally been confined to the linear, cross-sectional world (Martinez et al., 2005; Pastor \& Stambaugh, 2003; Acharya \& Pedersen, 2005). In this paper, we seek to fill this gap by testing the economically motivated hypothesis of nonlinearity in the relationship between systemic liquidity risk and asset prices (returns). We show how stock market returns are exposed to systemic liquidity risk during tail events and compare these outcomes with median market scenarios.

To test our hypothesis we build upon Fama \& French's (1993) traditional three-factor model augmented with the bid/ask based liquidity factor recently proposed by Abdi \& Ranaldo (2017). We conduct our estimations using quantile regressions, but rather than focusing on the cross-sectional effects (i.e. the cross-sectional liquidity premia associated with different portfolios at a given time), we fit quantile regressions to time-series returns.

By adopting this strategy we are able to isolate the effects of liquidity on different parts of the stock return distribution over time, which in turn, are naturally related to different market states. Notice, however, that the definition of 'market state' can be elusive. Cooper et al. 
(2004), for instance, define a good (bad) market state based on the average market return over the preceding three years. Pagan \& Sossounov (2003) and Edwards et al. (2003) define market states by locating turning points and the duration of peaks and troughs. However, these definitions are unnecessarily arbitrary given that the window widths are unjustified and selecting them may involve the cherry picking of results.

In contrast, using the market return quantiles of the probability distribution to define a market state is much less arbitrary. Quantiles-in-time can be considered as constituting a collection of market states, ranging from very good in the case of the highest quantiles (large positive returns) to very bad states in the case of the lowest quantiles (large negative returns). Being an order statistic that is robust to outliers, the independent estimation of different quantiles of the return distribution (conditional on relevant explanatory factors) has the advantage of allowing us to explore the full spectrum of the relationship between liquidity and stock returns.

Our results show that systemic liquidity risk is a price factor dependent on the market state. First, we show that when the market is in a bad state, systemic liquidity risk exhibits a negative relation with contemporaneous excess stock returns. Lower contemporaneous prices are naturally associated with higher future expected returns (under constant market fundamentals), which is consistent with the previous literature that assigns a positive premia to liquidity risk. Indeed, Amihud (2002) shows that unexpected market liquidity risk lowers contemporaneous stock prices, because a higher realized liquidity risk raises traders' expectations about future illiquidity in the market.

Second, we show that excess stock returns are positively related to systemic liquidity risk during good market states. This is at odds with the traditional understanding of the literature, because it means that conditional on a good market state a generalized increase in systemic illiquidity is associated with higher contemporaneous market returns (and hence lower expected returns under constant market fundamentals). This is a consequence of investors rebalancing their portfolios towards more illiquid assets when market performance is good, as occurs, for instance, when investors use excess gains to buy riskier and illiquid assets with search-for-yield considerations in mind.

Finally, we observe that during regular times (i.e. with quantiles close to the median), there is no significant relationship between systemic liquidity and market returns. This also challenges the traditional mean-to-mean effects reported in the literature that measures the importance of 
liquidity as an asset-pricing factor and restricts this importance to episodes of extreme realizations of market returns. Interestingly, unlike in the empirical literature, there are significant precedents in a series of theoretical studies that point to a nonlinear relationship between market liquidity and asset prices (see Vayanos, 2004; Morris \& Shin, 2004).

\section{Methodology}

\subsection{Systemic Liquidity}

To measure systemic liquidity risk, we employed the estimator proposed by Abdi \& Ranaldo (2017). This measure is based on close, high and low prices and bridges the well-known bidask spread (Roll, 1984) and the more recent high-low spread (Corwin \& Schultz, 2012). In comparison with other possible measures, this method makes use of wider information (i.e. close, high and low prices). Moreover, it presents the highest cross-sectional and average timeseries correlation with Trade and Quote's effective spread and provides the most accurate estimates for less liquid stocks.

The effective spread shares the same theoretical assumptions as Roll's spread (1984) and can be written as:

$$
s=2 \sqrt{E\left(c_{t}-\eta_{t}\right)\left(c_{t}-\eta_{t+1}\right)}
$$

where $c_{t}$ is the daily observed close log-price and $\eta_{t}$ represents the mid-range between daily high and low log-prices.

Following Corwin \& Schultz (2012), Abdi \& Ranaldo (2017) estimate the squared spread $s^{2}$ in (1) over two-day periods. If a two-day estimate is negative, they set it to zero. Second, they take the square root and then take the monthly average:

$$
s_{\text {monthlycorrected }}=\sqrt{\max \left\{4 \frac{1}{N} \sum_{t=1}^{N}\left(c_{t}-\eta_{t}\right)\left(c_{t}-\eta_{t+1}\right), 0\right\}}
$$

where $\mathrm{N}$ is the number of trading days in a month.

Finally, the monthly systemic liquidity risk indicator can be calculated as the equally weighted average of this monthly spread of individual stocks.

\subsection{Liquidity-Augmented Four-Factor Model}


We augmented Fama \& French's (1993) standard three-factor model with the systemic liquidity risk factor. The liquidity-augmented four-factor model can be written as follows:

$$
r_{i t}-r_{f t}=\beta_{1}^{L} L i q_{t}+\beta_{2}\left(r_{m t}-r_{f t}\right)+\beta_{3}(S M B)_{t}+\beta_{4}(H M L)_{t}+\varepsilon_{i t}
$$

where $\left(r_{i t}-r_{f t}\right)$ gives the monthly excess returns on 25 U.S. portfolios sorted according to size and book-to-market value $(\mathrm{BE} / \mathrm{ME})$ quintiles; the excess return on a broad market

portfolio is denoted as $\left(r_{m t}-r_{f t}\right) ; r_{f t}$ is the risk-free rate, proxied by the one-month treasury bill rate; $\varepsilon_{i t}$ is the error term, assumed to be independent with zero mean and variance $\sigma^{2}$. The factors $(\mathrm{SMB})$ and $(\mathrm{HML})$ are portfolios, mimicking the risk factor in returns related to size and book-to-market equity, respectively ${ }^{1} ; L_{i q}$ denotes the systemic liquidity risk measure, and the coefficient $\beta_{1}^{L}$ captures the sensitivity of excess returns on systemic liquidity in the market.

\subsection{Quantile Regression}

We adopt Koenker \& Bassett Jr's (1978) quantile regression technique (see also Koenker \& Hallock, 2001). Quantile regressions provide insights into the impact of explanatory variables on the entire conditional distribution of the response variable. In this setting, conditional quantile regressions are linear in parameters for each selected quantile.

Eq. (3) relates to the conditional mean scenario of excess returns and exposure to aggregate liquidity risk. To investigate excess returns across its conditional distribution, the time-series quantile liquidity-adjusted factor model for quantile $\tau$ can be written as follows:

$$
r_{i t}-r_{f t}=\beta(\tau) x_{i}+\varepsilon_{i}(\tau)
$$

where all quantile parameters are displayed in a vector $\beta(\tau)=\left\{\beta_{1}^{L}(\tau), \beta_{2}(\tau), \beta_{3}(\tau), \beta_{4}(\tau)\right\}$ and all factors in a $N \times 4$ matrix, denoted as $x_{i}=\left\{L i q_{t}, R M K T_{t}, S M B_{t}, H M L_{t}\right\}$. We assume that the vector of error terms conditioned on the parameter matrix is zero, $Q_{\tau}\left(\varepsilon_{i t \mid x i}=0\right)$. We can then specify the $\tau$ th conditional quantile function as follows:

$$
Q_{y}\left((\tau) \mid x_{i}\right)=\beta(\tau) x_{i}
$$

To obtain an estimate $\hat{\beta}(\tau)$ of the unknown coefficient(s) for the $\tau$ th quantile, the following function is minimized:

\footnotetext{
${ }^{1}$ See Fama \& French $(1992,1993,1996)$ for details about factor construction.
} 


$$
\hat{\beta}(\tau)=\operatorname{argmin} \sum_{i}^{n} \rho_{\tau}\left(\left(r_{i t}-r_{f t}\right)-\beta_{\tau} x_{i}\right)
$$

where $\rho_{\tau}(\mu)=\mu(\tau-I(\mu<0))$ with $0<\tau<1$ is a check function with asymmetric weights, which depend on the quantile selected. While we collect all quantile estimates in a set $\Phi=$ $\left\{\beta_{1}^{L}(\tau), \beta_{2}(\tau), \beta_{3}(\tau), \beta_{4}(\tau)\right\}$, we only report in the results section below the liquidity betas, $\beta_{1}^{L}(\tau)$, for every quantile ${ }^{2}$. The liquidity-adjusted three-factor model is estimated as a conditional quantile function at a range of quantiles, $\tau=(0.1-0.95)$, in 0.05 intervals.

\section{Data}

The portfolios used in our calculations include stocks from NYSE, AMEX and NASDAQ, and are constructed on a monthly basis from July of year $t$ to June of year $t+1$, spanning the period July 2000-December 2016. Subtracting the risk-free rate from the returns, the excess returns on 25 portfolios denote the dependent variable in a time-series setting. The measure for systemic liquidity risk was retrieved from the authors' webpage ${ }^{3}$. We standardized the liquidity measure to obtain comparable estimates with respect to the coefficients of the three factors commonly used in the literature. Data on the portfolios and the three factors were retrieved from Kenneth French's webpage ${ }^{4}$.

\section{Results}

Figure 1 summarizes the effects of liquidity on different quantiles of the excess stock return distribution over time. As is evident, the effects are highly nonlinear, ranging from negative to positive as market returns increase.

\footnotetext{
${ }^{2}$ We do not provide estimates of the factor-portfolios (three factors) as they have been widely documented in the respective literature, see, for example, Fama \& French (2016). The results are available upon request.

${ }^{3}$ https://sbf.unisg.ch/en/lehrstuehle/lehrstuhl_ranaldo/homepage_ranaldo/research-material

${ }^{4}$ http://mba.tuck.dartmouth.edu/pages/faculty/ken.french/datalibrary:html
} 


\section{Figure 1. Systemic Liquidity Effects on Excess Market Returns}

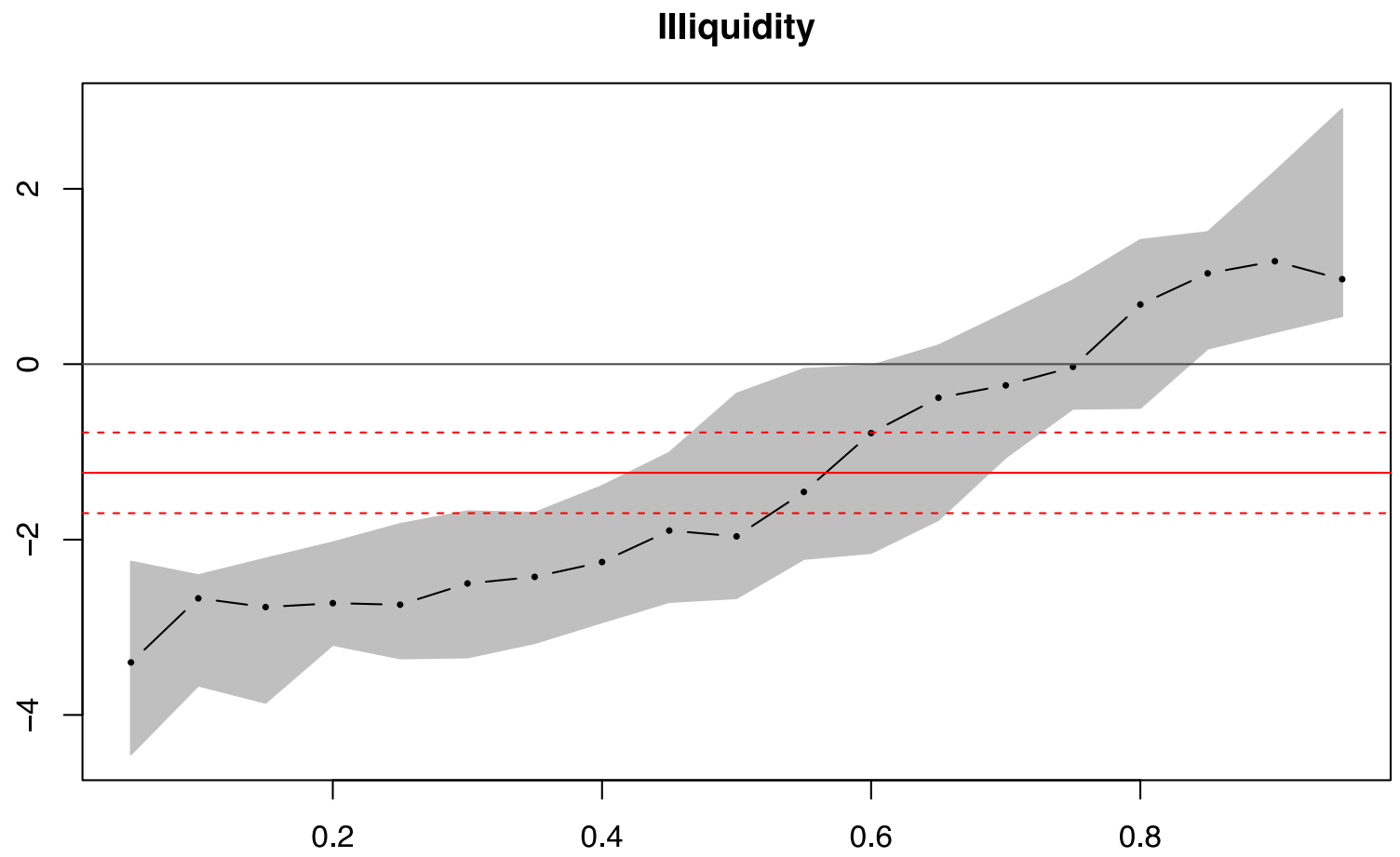

Note: The figure shows the effects of liquidity on excess market returns from January 2000 to December 2016. The linear effect is indicated by the solid red line accompanied by two parallel dotted lines, representing the $95 \%$ confidence intervals of the regression. The effects of liquidity risk under different quantiles of the market return are captured by the dash-dotted black line accompanied by the associated bootstrapping confidence intervals of the quantile regressions (gray-shaded area).

Panel A of Figure 2 presents the liquidity betas of 25 value-weighted U.S. portfolios sorted according to size and book-to-market criteria. The $\mathrm{x}$-axis denotes the portfolio (from small-low portfolios to big-high portfolios) and the y-axis corresponds to the quantiles. Lower quantiles are associated with bad market states (darker shades through to red), while higher quantiles are associated with good market states (lighter shades through to yellow). Panel B presents a binary visualization of the associated t-statistics of the quantile regressions, where 1 - depicted in black - indicates whether the respective liquidity estimate made in the same coordinates of Panel A is statistically different from zero and 0 - depicted in white, indicates just the contrary. All the conclusions reached in this section are found to hold after controlling for such factors as size, value, and momentum, different industries, different portfolio types, and different sample periods (results are available on request).

Figure 2 shows the transition of the liquidity betas associated with the systemic liquidity factor across states and across portfolios. We document a clear pattern across market states, but we 
are unable to extract a reliable pattern across portfolios. We find that systemic liquidity risk tends to produce an effect on portfolio returns, with estimates ranging from -1.3 to 2.6. The sign and significance of these effects clearly depend on the market state. On the one hand, the coefficients tend to be negative for bad market states and positive for good market states. This means that an increase in illiquidity when the market is experiencing losses hurts the portfolio performance and that an increase in illiquidity busts portfolio returns when the market is experiencing gains.

The effect of systemic liquidity risk on portfolio returns lying close to the median is, by general rule, statistically equal to zero. This result is consistent with the findings of Watanabe \& Watanabe (2007). This authors find that cross-sectional liquidity betas vary over time, resulting in two distinct liquidity states and show that during ordinary transaction months, the pricing of illiquidity in the market is quite flat across portfolios. This contrasts with what these authors document for high liquidity states, when liquidity risk premia are disproportionately large.

In episodes of extreme market turmoil, when the markets are experiencing significant and recurring losses, market-wide liquidity falls dramatically. The negative spirals documented in the literature as emerging between funding liquidity and market-wide liquidity may lead traders to engage in fire sales or precautionary transactions, as they seek to avoid expected margin calls. This situation is in turn accompanied by an increase in preference uncertainty, market sentiment and, in general, a deterioration in future economic outlooks. All these reasons have been documented previously in the literature and are in line with an increasing appetite for safe and liquid assets. Moreover, they point to a contemporaneous reduction in market prices, following an increase in generalized market illiquidity. Such reductions are to be found in the left tail of the returns distribution, which correspond to its lowest quantiles. As can be observed in Figure 2, the lower the quantile, the higher is the negative impact of liquidity risk on the contemporaneous stocks returns.

The positive effects in the right tail of the return distribution implies that when the market state is good (positive large returns), traders perceive liquidity as a relevant factor to inform their decisions about portfolio composition. This situation is expected in a search-for-yield scenario, in which investors start to rebalance their portfolios in an opposite way to the strategy they adopt during a bad market state. Thus, they rebalance towards riskier and less liquid assets, which can provide greater returns. This is generally the case when market and 
funding liquidities are both perceived as sufficiently high and, therefore, traditional and safe assets yield unusually low gains, which traders aim to offset by resorting to less liquid and riskier assets. If market portfolios consist of these risker and less liquid assets, returns naturally increase, as traditional compensation for risk demands, at the same time as market-wide liquidity falls.

Our results show that for most of the quantiles - essentially between $\tau=(0.35)$ and $\tau=(0.75)$ - the effects of market-wide liquidity on excess returns are statistically equal to zero. Thus, market-wide liquidity is not priced by the market when the market state is regular. This result challenges the traditional belief that commonality and market-wide liquidity risk are determinants of asset prices. 
Figure 2. Systemic Liquidity Betas according to market states

Panel A

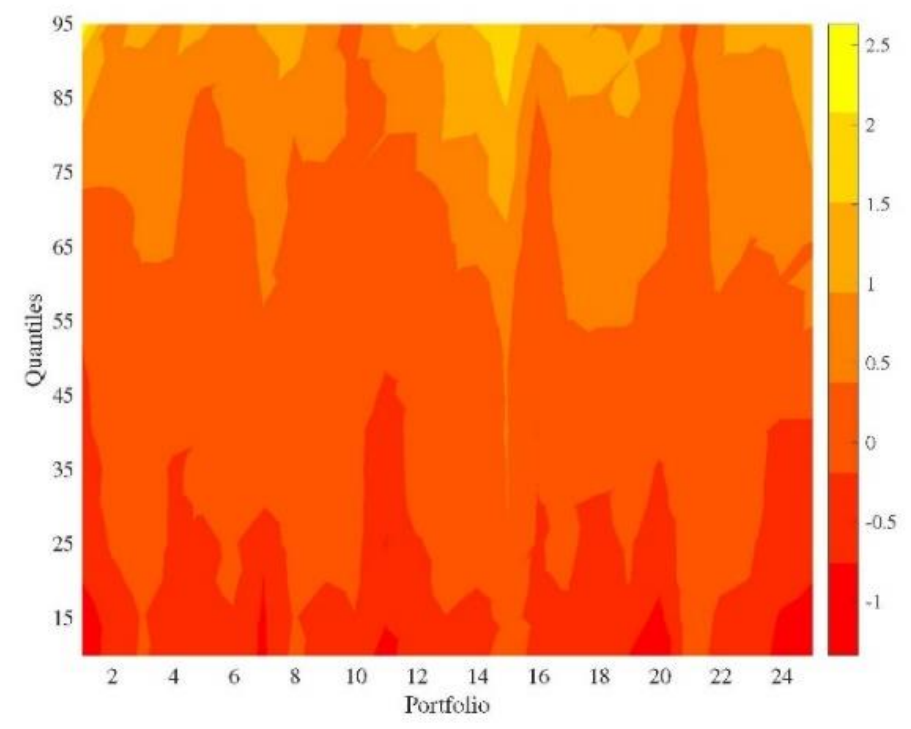

Panel B

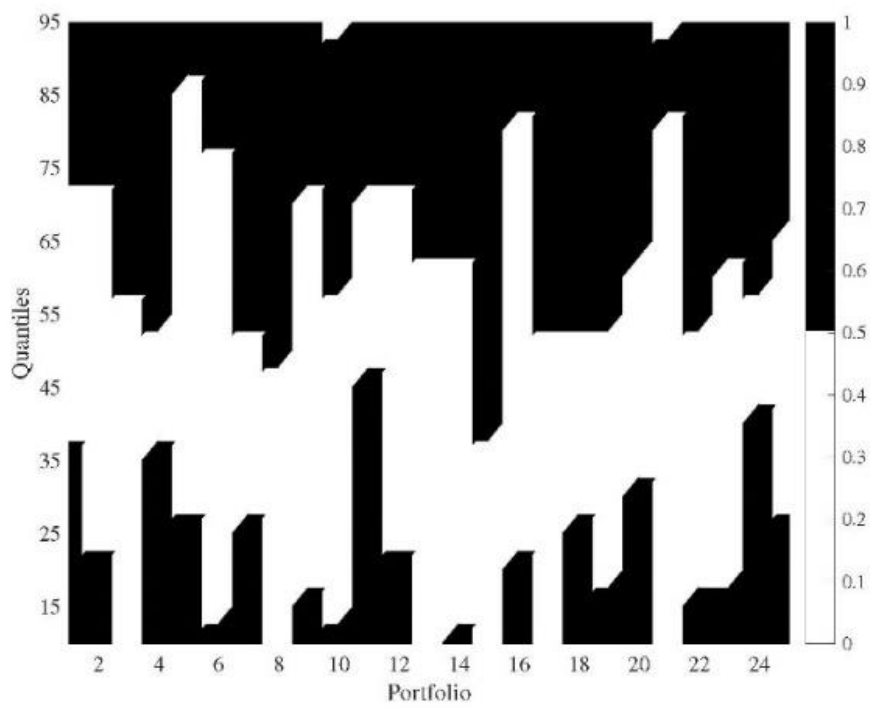

Note: Panel A shows the liquidity betas for $\tau=0.1-0.95$ in 0.05 intervals, for all 25 portfolios. Panel B presents the corresponding t-statistics of the liquidity betas. The black-shaded area is defined as being statistically significant at the $5 \%$ level whereas the white-shaded area corresponds to insignificant coefficients associated with the liquidity betas. 


\section{Conclusion}

We find that for most portfolios, the effects of liquidity risk on excess returns exhibit a nonlinear pattern. In markets experiencing gains, we show that contemporaneous returns are positively associated with systemic liquidity risk. That is, market participants care about appropriate compensations for any illiquid position in the market that they are willing to buy. In contrast, we observe that in bearish markets systemic liquidity risk is negatively associated with returns, which, in line with the previous literature, translates into higher expected returns for illiquid assets. This can be explained by investors' shifting risk preferences and uncertainty about the variability and timing of illiquidity events, resulting in downward effects on asset prices. During regular times, the market rarely prices liquidity risk. This shows that investors are less concerned about illiquidity in untroubled market states, corresponding to returns around the median.

\section{References}

Abdi, F., \& Ranaldo, A. (2017). A simple estimation of bid-ask spreads from daily close, high, and low prices. The Review of Financial Studies, 30(12), 4437-4480.

Acharya, V. V., \& Pedersen, L. H. (2005). Asset pricing with liquidity risk. Journal of Financial Economics, 77(2), 375-410.

Amihud, Y. (2002). Illiquidity and stock returns: cross-section and time-series effects. Journal of Financial Markets, 5 (1), 31-56.

Amihud, Y., Mendelson, H., \& Pedersen, L. H. (2005). Liquidity and asset pricing. Foundations and Trends in Finance, 1(4), 269-364.

Baele, L., Bekaert, G., Inghelbrecht, K., \& Wei, M. (2013). Flights to safety (No. w19095). National Bureau of Economic Research.

Beber, A., Brandt, M. W., \& Kavajecz, K. A. (2008). Flight-to-quality or flight-to-liquidity? Evidence from the euro-area bond market. The Review of Financial Studies, 22(3), 925-957.

Cooper, M. J., Gutierrez Jr, R. C., \& Hameed, A. (2004). Market states and momentum. The Journal of Finance, 59(3), 1345-1365.

Corwin, S. A., \& Schultz, P. (2012). A simple way to estimate bid-ask spreads from daily high and low prices. The Journal of Finance, 67(2), 719-760.

Edwards, S., Biscarri, J. G., \& De Gracia, F. P. (2003). Stock market cycles, financial liberalization and volatility. Journal of International Money and Finance, 22(7), 925-955. 
Fama, E. F., \& French, K. R. (1992). The cross- section of expected stock returns. The Journal of Finance, 47(2), 427-465.

Fama, E. F., \& French, K. R. (1993). Common risk factors in the returns on stocks and bonds. Journal of Financial Economics, 33(1), 3-56.

Fama, E. F., \& French, K. R. (1996). Multifactor explanations of asset pricing anomalies. The Journal of Finance, 51(1), 55-84.

Fama, E. F., \& French, K. R. (2016). Dissecting anomalies with a five-factor model. The Review of Financial Studies, 29(1), 69-103.

Fratzscher, M., Lo Duca, M., \& Straub, R. (2018). On the International Spillovers of US Quantitative Easing. The Economic Journal, 128, 330-377.

Hameed, A., Kang, W., \& Viswanathan, S. (2010). Stock market declines and liquidity. The Journal of Finance, 65(1), 257-293.

Kiendrebeogo, Y. (2016). Unconventional monetary policy and capital flows. Economic Modelling, 54, 412-424.

Koenker, R., \& Bassett Jr, G. (1978). Regression quantiles. Econometrica, 33-50.

Koenker, R., \& Hallock, K. F. (2001). Quantile regression. Journal of Economic Perspectives, 15(4), 143-156.

Martınez, M. A., Nieto, B., Rubio, G., \& Tapia, M. (2005). Asset pricing and systematic liquidity risk: An empirical investigation of the Spanish stock market. International Review of Economics and Finance, 14(1), 81-103.

Morris, S., \& Shin, H. S. (2004). Liquidity black holes. Review of Finance, 8(1), 1-18.

Pagan, A. R., \& Sossounov, K. A. (2003). A simple framework for analysing bull and bear markets. Journal of Applied Econometrics, 18(1), 23-46.

Pastor, L., \& Stambaugh, R. F. (2003). Liquidity risk and expected stock returns. Journal of Political Economy, 111(3), 642-685.

Roll, R. (1984). A simple implicit measure of the effective bid-ask spread in an efficient market. The Journal of Finance, 39(4), 1127-1139.

Vayanos, D. (2004). Flight to quality, flight to liquidity, and the pricing of risk (No. w10327). National Bureau of Economic Research.

Watanabe, A., \& Watanabe, M. (2007). Time-varying liquidity risk and the cross section of stock returns. The Review of Financial Studies, 21(6), 2449-2486. 